\title{
Fertility of bull spermatozoa in egg-yolk diluents of varied lipid fatty acid composition
}

\author{
J. A. Foulkes, D. Sweasey* and R. G. Goodey \\ Cattle Breeding Centre, Shinfield, Reading RG2 9BZ, and *Central Veterinary Laboratory, \\ New Haw, Weybridge KT15 3NB, U.K.
}

\begin{abstract}
Summary. Three groups of hens were fed a standard egg-production mixture or similar diets enriched with either sunflower oil or beef tallow. The resulting egg yolks were used to prepare bovine semen diluents. Changes in the lipid fatty acid composition of the diluents were demonstrated by gas-liquid chromatography. No significant effects of the treatments were seen on bovine sperm motility after freezing and thawing, or on fertility.
\end{abstract}

\section{Introduction}

The yolk of hen eggs is widely regarded as an essential ingredient of diluents for the freezing of bovine semen, apparently providing protection to sperm membranes against cold shock and damage during cooling, freezing and thawing. Smith \& Back (1975) demonstrated that an increase in the lipid-bound polyunsaturated fatty acid content of egg yolk reduced the temperature at which irreversible gelation and aggregation of its lipoprotein occurred. Similarly, Shenstone \& Burley (1975) have shown that feeding methyl sterculate to hens resulted in changes in the egg yolk gelation temperature paralleling alterations in the proportion of saturated fatty acids present in their lipids. In the present experiments hens were fed different diets to alter the proportion of lipid fatty acids in the yolks. These yolks were used in diluents for bovine spermatozoa to examine sperm survival after freezing and thawing and determine fertility in a field trial.

\section{Materials and Methods}

\section{Egg production}

Three groups of hens (Warren SSLF) were separately housed and fed one of the 3 diets given in Table 1 for 1 month before the start of egg collection. The control diet was a standard mix fed for commercial egg production. The sunflower oil diet was intended to increase the polyunsaturated fatty acid component, and the beef tallow diet to raise the level of saturated fatty acids in the egg yolks.

\section{Fatty acid determination}

Lipid was extracted from diluent prepared with the eggs from the 3 groups of hens by shaking with 4 volumes of chloroform: methanol $(2: 1 \mathrm{v} / \mathrm{v})$ using methods previously reported (Foulkes, 1977). The fatty acid composition of the total lipid extract was determined as follows. Fatty acid methyl esters were formed by reacting aliquots of the lipid extract with $14 \%$ boron trifluoride in 
Table 1. Composition of experimental diets

\begin{tabular}{lccc}
\hline & \multicolumn{3}{c}{ Diets (\% by weight) } \\
\cline { 2 - 4 } & Control & Sunflower oil & Beef tallow \\
\hline Ground wheat & 34 & 59 & 59 \\
Ground maize & 40 & - & - \\
Sunflower oil & - & 15 & - \\
Beef tallow & - & - & 15 \\
Soya bean meal & 10 & 10 & 10 \\
White fish meal & 5 & 5 & 5 \\
Dried grass meal & 2.50 & 2.50 & $2 \cdot 50$ \\
Limestone flour & 7.50 & 7.50 & 7.50 \\
Dicalcium phosphate & 0.35 & 0.35 & 0.35 \\
Sodium chloride & 0.40 & 0.40 & 0.40 \\
Beecham Microcon 8105 & 0.25 & 0.25 & 0.25 \\
$\quad$ (vitamins and trace elements) & & & \\
\hline
\end{tabular}

methanol in an atmosphere of nitrogen for $1 \mathrm{~h}$ at $100^{\circ} \mathrm{C}$. Gas-liquid chromatography (g.l.c.) of the methyl esters was carried out isothermally using a gas chromatograph (Model 104, Pye Unicam Ltd, Cambridge, U.K.) equipped with a flame ionization detector. Columns treated with dimethyl dichlorosilane $(182 \times 0.4 \mathrm{~cm}$ internal diameter) were packed with $10 \%$ EGSS-X or 10\% SILAR-10C on 100/120 mesh GAS-CHROM Q (Applied Science Laboratories Europe Ltd, P.O. Box 1149, Oud-Beijerland, Holland). Column temperatures were 200 and $180^{\circ} \mathrm{C}$ respectively with the detector temperature maintained at $250^{\circ} \mathrm{C}$. Peaks of the individual fatty acids were identified by comparison with the retention times of known standard fatty acid methyl esters (Applied Science Laboratories Ltd) and quantitated using an automatic digital integrator (Model CRS-208, Infotronics U.K. Ltd, Stone, U.K.).

\section{Semen preparation and tests}

The egg-yolk diluent composition was $20 \%(\mathrm{v} / \mathrm{v})$ egg yolk, $75.3 \%(\mathrm{v} / \mathrm{v})$ lactose solution $(11 \mathrm{~g} / 100 \mathrm{ml})$ and $4.7 \%(\mathrm{v} / \mathrm{v})$ glycerol with $500 \mu \mathrm{g}$ streptomycin sulphate/ml (Foulkes, Goodey \& Stewart, 1977a).

Semen was collected from 5 Friesian bulls by means of an artificial vagina and sperm motility was estimated independently by 2 experienced observers using a microscope and warm stage at $40^{\circ} \mathrm{C}$. The semen was maintained at $30^{\circ} \mathrm{C}$ and each ejaculate was divided between the three diluents before cooling to $5^{\circ} \mathrm{C}$ over $30 \mathrm{~min}$. Semen was equilibrated for $6 \mathrm{~h}$ at $5^{\circ} \mathrm{C}$ and $0.25 \mathrm{ml}$ polyvinyl chloride straws were filled and sealed to provide $20 \times 10^{6}$ spermatozoa/straw. Semen was frozen on horizontal racks $4 \mathrm{~cm}$ above the surface of liquid nitrogen. A temperature of $-120^{\circ} \mathrm{C}$ was attained in $7 \mathrm{~min}$ and the straws were then transferred to a goblet containing liquid nitrogen. Eleven inseminators were supplied with an equal number of coded straws from each ejaculate and treatment diluent and used them to inseminate unselected Friesian cows of known identity. Only first services were employed and the number of cows not returning to service in the 16 weeks following insemination was recorded as a measure of fertility. Two straws from each ejaculate and treatment were thawed, diluted in 2 volumes of $3 \%(\mathrm{w} / \mathrm{v})$ tri-sodium citrate, $\mathrm{pH} 7.0$ (Foulkes, Goodey \& Stewart, 1977b), and sperm motility was determined 'blind' by the same 2 observers.

\section{Results}

The diluents prepared with eggs from the 3 groups of hens showed differences in the proportion of lipid-bound fatty acids present (Table 2). Feeding of the tallow diet significantly increased the proportion of monounsaturated fatty acids present notably in the $18,1_{1}$ group, when compared 
Table 2. Mean \pm s.d. distribution (\%) of lipid fatty acids in diluents prepared from egg yolks of hens fed different diets

\begin{tabular}{cccc}
\hline $\begin{array}{c}\text { Fatty acid } \\
\text { chain length and } \\
\text { saturation }\end{array}$ & $\begin{array}{c}\text { Control } \\
(n=8)\end{array}$ & $\begin{array}{c}\text { Sunflower oil } \\
(n=7)\end{array}$ & $\begin{array}{c}\text { Tallow } \\
(n=8)\end{array}$ \\
\hline $14: 0$ & $0.2 \pm 0.06$ & $* * 0.12 \pm 0.03$ & $* * 0.3 \pm 0.04$ \\
$14: 1$ & 0.10 & $* * 21.7 \pm 1.83$ & $24.8 \pm 1.46$ \\
$16: 0$ & $25.9 \pm 1.48$ & $* * * 2.1 \pm 0.31$ & $4.6 \pm 0.39$ \\
$16: 1$ & $5.2 \pm 0.77$ & $* * 9.0 \pm 0.73$ & $8.0 \pm 0.52$ \\
$18: 0$ & $7.8 \pm 0.73$ & $* * * 37.1 \pm 1.20$ & $* * 52.0 \pm 2.41$ \\
$18: 1$ & $47.7 \pm 2.25$ & $* * * 27.9 \pm 2.81$ & $8.1 \pm 2.46$ \\
$18: 2$ & $10.9 \pm 2.49$ & $* 0.3 \pm 0.05$ & $0.5 \pm 0.13$ \\
$18: 3$ & $0.6 \pm 0.39$ & - & \pm \\
$18: 4$ & - & - & $1.4 \pm 0.56$ \\
$20: 1$ & $1.5 \pm 0.34$ & $1.8 \pm 0.39$ & 13 \\
$20: 3$ & $34.1 \pm 1.12$ & $* * 30.9 \pm 2.27$ & $33.1 \pm 1.47$ \\
\hline Saturated & $53.2 \pm 2.04$ & $* * * 39.4 \pm 1.45$ & $* * 56.9 \pm 2.47$ \\
Monounsaturated & $12.7 \pm 3.08$ & $* * 29.7 \pm 3.35$ & $10.0 \pm 2.94$ \\
Polyunsaturated & & &
\end{tabular}

Values are mean percentage distribution \pm s.d.

Significantly different from control value: ${ }^{*} P<0.05$; ${ }^{* *} P<0.01$; ${ }^{* * *} P<0.001$ (Student's $t$ test).

Table 3. Mean motility (\% cells motile) of bull spermatozoa immediately after collection and after freezing and thawing

\begin{tabular}{cccccc}
\hline & & & \multicolumn{3}{c}{ After thawing } \\
\cline { 4 - 6 } Bull & $\begin{array}{c}\text { No. of } \\
\text { ejaculates }\end{array}$ & $\begin{array}{c}\text { After } \\
\text { collection }\end{array}$ & Control & $\begin{array}{c}\text { Sunflower } \\
\text { oil }\end{array}$ & Tallow \\
\hline A & 5 & 44.5 & 34 & 36 & 35.5 \\
B & 5 & 40 & 30 & 30 & 25 \\
C & 5 & 33 & 24 & 24 & 21.5 \\
D & 2 & 42.5 & 35 & 32.5 & 38.8 \\
E & 3 & 50 & 40 & 34.1 & 36 \\
\hline Total & 20 & 41.1 & 31.5 & 30.9 & 29.5 \\
\hline
\end{tabular}

Table 4. Non-return rates (\%) of cows 16 weeks after insemination with semen diluted in diluents prepared with eggs from hens fed different diets

\begin{tabular}{|c|c|c|c|c|}
\hline \multirow[b]{3}{*}{ Bull } & \multicolumn{4}{|c|}{ Diet } \\
\hline & Control & $\begin{array}{l}\text { Sunflower } \\
\text { oil }\end{array}$ & Tallow & Total \\
\hline & No. (\%) & No. (\%) & No. (\%) & No. (\%) \\
\hline A & $480(63 \cdot 1)$ & $482(67 \cdot 2)$ & $445(60 \cdot 9)$ & $1407(63 \cdot 8)$ \\
\hline B & $480(61 \cdot 9)$ & $469(55 \cdot 4)$ & $488(56 \cdot 6)$ & $1437(57.9)$ \\
\hline $\mathrm{C}$ & $483(57.8)$ & $481(57.0)$ & $484(57.9)$ & $1448(57 \cdot 5)$ \\
\hline D & $196(59 \cdot 7)$ & $235(56 \cdot 2)$ & $243(63.4)$ & $674(59.8)$ \\
\hline $\mathrm{E}$ & $284(64 \cdot 4)$ & $281(66.9)$ & $271(66 \cdot 1)$ & $836(65 \cdot 8)$ \\
\hline Total & $1923(61 \cdot 3)$ & $1948(60 \cdot 5)$ & $1931(60 \cdot 1)$ & $5802(60 \cdot 6)$ \\
\hline
\end{tabular}

There was significant variation between individual bulls $\left(\chi^{2}=25.5 ; P<0.001\right)$. 
with the control diet. The sunflower oil diet produced more widespread changes, including reduction in the proportion of saturated and monounsaturated fatty acids and a large increase in the proportion of polyunsaturated fatty acids.

The effect of these diluent differences on the post-thaw motility of spermatozoa was examined in each ejaculate from each bull. Although differences in sperm survival were apparent between bulls, no significant diluent effect could be determined (Table 3).

Field results obtained in the split-ejaculate fertility trial were analysed for the effects of inseminator, bull, ejaculate and treatment. Significant variation was found between inseminators and between bulls but there was no interaction with treatment. There was no evidence that changing the fatty acid composition of egg yolk used in diluents for freezing semen affected either the overall fertility or the performance of individual bulls (Table 4).

\section{Discussion}

There is a degree of conflict over the optimal structure of membranes to resist damage during cooling. Increases in the polyunsatutated fatty acid content have been associated with increases in yeast cell survival after freezing (Kruuv, Lepock \& Keith, 1978) and with the development of frost-hardiness in plants (Farkas, Vigh, Horvath \& Belea, 1978), although this has been questioned (Singh, de la Roche \& Siminovitch, 1977). Poulos, Darin-Bennett \& White (1973) and Darin-Bennett, Poulos \& White (1974a, b) have presented circumstantial evidence to suggest that spermatozoa exhibiting a low polyunsaturated fatty acid:saturated fatty acid ratio in their phospholipids survive temperature changes more readily.

Egg yolk provides good protection to bovine spermatozoa during cooling, freezing and thawing. Previous experiments have demonstrated that lipoproteins separated from egg yolk by centrifugation and column chromatography become bound to bovine spermatozoa (Foulkes, 1977) and that semen diluted with diluent containing egg-yolk lipoproteins exhibited fertility levels indistinguishable from those with control diluent containing egg yolk when used in the field (Foulkes \& Stewart, 1977). Kruuv et al. (1978) showed that the freeze-thaw survival of yeast cells could be altered by growing the cells in media containing stearolic acid or linolenic acid and that this was related to changes in membrane fluidity. If sperm membranes become damaged as a result of their lipids undergoing a phase transition in the early part of the cooling procedure, then the binding of egg-yolk lipoproteins may prevent this by altering the membrane composition and thus its phase transition temperature.

The increases in the polyunsaturated fatty acid content of the lipids of diluents prepared with eggs from hens fed the diet including sunflower oil were marked and comparable with those reported by other workers (Posati, Kinsella \& Watt, 1975). There was, however, no measurable effect from these changes on the post-thaw motility of spermatozoa or their subsequent fertility. This would argue against an enhanced protective effect by polyunsaturated fatty acid-containing lipids for the membrane. Diluent prepared with eggs obtained after the inclusion of a large proportion of saturated fatty acid in the diet was equally ineffective in improving sperm survival, but only small changes had been effected in the diluent fatty acid composition (Table 2).

The yolk of hen eggs may fortuitously possess a fatty acid content conducive to the protection of bovine spermatozoa. The normal diet fed to the hens supplying this laboratory with eggs for diluents and which served as the control diet in these experiments has a high content of maize meal and itself supplied a measure of polyunsaturated fat to the control diluent $(12.7 \%$ of total lipid fatty acids, Table 2). Comparison of the fatty acid complement of lipids in the control diluent with the phospholipid fatty acid content determined in bull spermatozoa (Poulos et al., 1973) demonstrates large differences in composition. The chief fatty acid $(61.3 \%)$ found in phospholipids from bovine spermatozoa was the highly unsaturated docosahexaenoic acid. Saturated fatty acids totalled $21.4 \%$ and monounsaturated fatty acids were confined to $5.7 \%$ 
oleic acid. By contrast, egg yolk lipids contained $34 \cdot 1 \%$ saturated and $53 \cdot 2 \%$ monounsaturated fatty acids (Table 2) and these components may be those instrumental in providing protection for the spermatozoa. The diet enriched with tallow did not promote a sufficiently radical change in the unsaturated:saturated fatty acid ratio to allow the effect of increased saturation to be assessed, perhaps as a result of the presence of the significant quantities of maize meal. A revised diet might allow this end of the saturation spectrum to be more satisfactorily examined. For example, feeding methyl sterculate to hens results in a saturated fatty acid content in egg-yolk lipid of over $60 \%$ (Shenstone \& Burley, 1975).

An alternative mode of action of egg yolk in stabilizing membrane structure was suggested by the observations of Darin-Bennett \& White $(1975,1977)$ that there was an apparent correlation between the cholesterol content of spermatozoa from various species and their ability to withstand cold shock. Egg yolk and its lipoproteins have significant levels of cholesterol (Powrie, 1968; Shenstone, 1968) and it may be that their effectiveness is related to its presence. No evidence was obtained, however, for the selective binding of particular lipids to spermatozoa in earlier investigations (Foulkes, 1977).

We thank Mr L. Marsden and the staff of Lane End Farm, University of Reading, for the eggs, and Mr T. G. Debney for his assistance with the motility determinations.

\section{References}

Darin-Bennett, A. \& White, I.G. (1975) Cholesterol and phospholipid content of mammalian spermatozoa and its relation to membrane structure and cold shock. J. Reprod. Fert. 43, 383-384.

Darin-Bennett, A. \& White, I.G. (1977) Influence of the cholesterol content of mammalian spermatozoa on susceptibility to cold-shock. Cryobiology 14, 466470 .

Darin-Bennett, A., Poulos, A. \& White, I.G. (1974a) The phospholipids and phospholipid-bound fatty acids and aldehydes of dog and fowl spermatozoa. $J$. Reprod. Fert. 41, 471-474.

Darin-Bennett, A., Poulos, A. \& White, I.G. (1974b) Interspecies differences in the phospholipid-bound fatty acid patterns of mammalian spermatozoa. Proc. Aust. Biochem. Soc. 7, 39.

Farkas, T., Vigh, L., Horvath, I. \& Belea, A. (1978) Metabolism of linolenic acid in a cold-sensitive (Penyama 62) and a cold resistant (Miranovskaja 808) wheat cultivar. Cryobiology 15, 569-577.

Foulkes, J.A. (1977) The separation of lipoproteins from egg-yolk and their effect on the motility and integrity of bovine spermatozoa. J. Reprod. Fert. 49, 277284.

Foulkes, J.A. \& Stewart, D.L. (1977) Fertility of dairy cattle after artificial insemination with semen frozen in a lipoprotein diluent. J. Reprod. Fert. 51, 175-177.

Foulkes, J.A., Goodey, R.G. \& Stewart, D.L. (1977a) Fertility of bovine semen frozen in four diluents for use in artificial insemination. Vet. Rec. 101, 171.

Foulkes, J.A., Goodey, R.G. \& Stewart, D.L. (1977b) Lactose based diluents in dairy cattle AI. Vet. Rec. $101,336$.
Kruuv, J., Lepock, J.R. \& Keith, A.D. (1978) The effect of fluidity of membrane lipids on freeze-thaw survival of yeast. Cryobiology 15, 73-79.

Posati, L.P., Kinsella, J.P. \& Watt, B.K. (1975) Eggs and egg products. III. Comprehensive evaluation of fatty acids in foods. J. Am. Diet. Assoc. 67, 111-115.

Poulos, A., Darin-Bennett, A. \& White, I.G. (1973) The phospholipid-bound fatty acids and aldehydes of mammalian spermatozoa. Comp. Biochem. Physiol. 46, 541-549.

Powrie, D. (1968) Gelation of egg yolk upon freezing and thawing. In Recent Advances in Food Science, Vol. 4. Low Temperature Biology and Foodstuffs, pp. 319-331. Eds J. Hawthorne \& E. J. Rolfe. Pergamon Press, Oxford.

Shenstone, F.S. (1968) The gross composition, chemistry and physico-chemical basis of organization of the yolk and white. In Egg Quality: a Study of the Hen's Egg, pp. 26-58. Ed. T. S. Carter. Oliver \& Boyd, Edinburgh.

Shenstone, F.S. \& Burley, R.W. (1975) Variable effects on egg yolk and yolk lipoprotein fractions of feeding methyl sterculate to hens: periodic changes in lipid composition and gelation temperature. J. Sci. $F d$ Agric. 26, 285-294.

Singh, J., de la Roche, I.A. \& Siminovitch, D. (1977) Differential scanning calorimeter analysis of membrane lipids isolated from hardened and unhardened black locust bark and from winter rye seedlings. Cryobiology 14, 620-624.

Smith, M.B. \& Back, J.F. (1975) Thermal transition in the low density lipoproteins and lipids of the egg yolk of hens. Biochim. Biophys. Acta 388, 203-212. 